\title{
O CANTO DA FAMÍLIA: ORGANIZAÇĀO VOCAL NAS FOLIAS DE REIS DO SUDESTE BRASILEIRO
}

\author{
Suzel Ana Reily*
}

\begin{abstract}
RESUMO
Trata-se de uma análise etnomusicológica das Folias da regiāo do Sudeste brasileiro. As Folias são compostas por grupos de músicos que fazem suas peregrinaçōes de casa em casa na época de Natal, como forma de devoção aos Três Reis Magos. Na tentativa de compreender a lógica por trás da distribuição das vozes nestes conjuntos, concentramos a análise sobre o estilo que os foliōes chamam de "toada velha", por ela ser a forma mais complexa do gênero encontrada na regiäo pesquisada. Como percebemos que a organização vocal reflete noşōes normativas referentes à estrutura familiar entre as comunidades que participam da tradiçāo, podemos ver a música como uma construçāo social, em que o grupo diz algo fundamental sobre a sua visāo de mundo.
\end{abstract}

Unitermos: Folia de Reis - Etnomusicologia-Estrutura familiar-Coesāo social

De longe, ouve-se a "xula dos palhaços", anunciando que a folia de Reis está chegando. Na frente do cortejo vem o bandeireiro, carregando o estandarte, objeto sagrado da companhia, em que há uma representação dos Três Reis diante do presépio de Belém. Atrás da Bandeira estão os palhaços (ou Bastiāo, como são chamados em algumas folias), com suas "fardas" floridas e máscaras grotescas (isto $e$, seus "capacetes"), que vêm dançando no seu passo saltitante para animar o grupo. Depois vêm os dois cordōes de músicos, mais ou menos enfileirados de acordo com a voz que cada um canta ou

(*) Doutoranda do Departamento de Antropologia da Faculdade de Filosofia, Letras e Ciências Humanas da USP. 
instrumento que toca no conjunto. De toda parte surge uma pequena multidão, sobretudo de crianças, que quer ver o que está acontecendo na rua.

O cortejo se aproxima de uma casa e seu dono vem para o portão, toma a Bandeira e leva-a para dentro. Os palhaços e os músicos seguem sua "guia" para o interior da casa e, aí então, começa a cantoria.

Quando há um presépio na casa, os palhaços tiram seus capacetes e se ajoelham diante da lapa, enquanto os músicos cantam uma série de versos em que narram sua interpretação da jornada dos Três Reis, rumo a Belém, e do nascimento do Menino Jesus. Terminada esta cantoria, há folias em que, ainda diante do presépio, os "Bastiāo" recitam as profecias, longas seqüências de versos que relatam episódios relacionados ao nascimento.

Após os rituais em torno do presépio, os palhaços se levantam, recolocam suas máscaras e o grupo retoma sua cantoria, desta vez dedicando um verso para cada morador da casa, sendo que a seqüência em que as pessoas recebem os versos explicita a concepção normativa do grupo referente à hierarquia familiar. Canta-se primeiramente para o dono da casa, depois para sua senhora, seguidos pelos filhos, outros parentes que se encontram na casa e, por fim, canta-se para os familiares falecidos. Aquele que está recebendo o verso "vai para a Bandeira", para segurá-la, sendo que, com este "sacramento" mágico, a pessoa recebe a bênção dos "Santo Reis". Os músicos pedem uma esmola, de modo a estabelecer uma relação de reciprocidade entre os devotos e o sagrado (Brandāo, 1981; Zaluar, 1983), e este dinheiro é empregado na realização da Festa da Chegada, que deveria ocorrer no dia 6 de janeiro. ${ }^{1}$ A esmola $e ́$ devidamente agradecida, também através de cantoria, aproveitando-se o momento para convidar a familia a participar do evento coletivo para o qual está contribuindo.

Esta cena se repete horas a fio, todos os anos durante os doze dias da jornada em vários cantos do território nacional, seja na zona rural, seja na cidade grande, começando "da meia noite por dia" do dia 25 de dezembro. 2

Vendo esta seqüência no seu conjunto, pode-se dizer que o grupo canta primeiramente para a Sagrada Família no presépio, seguido por uma cantoria individualizada para cada membro de uma família nuclear. Para completar o ciclo, a jornada culmina com uma festa em que se celebra a grande "família de Deus" na terra.

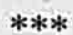

Dada a difusão da tradição por todo o Brasil, não surpreende constatar que haja uma bibliografia relativamente extensa sobre o tema (Brandão, 1977 e 1981; Castro e Couto, 1977; Porto, 1982; Araújo, 1950 e 1964; Tavares de Lima, 1981; entre muitos outros). No entanto, nāo há, entre esses trabalhos todos, um sequer que procure analisar, sociologicamente, seus aspectos musicais enquanto expressão de uma visão do mundo e de um ethos, embora um dos elementos centrais da tradição seja a sua performance musi-

(1) Como dia 6 de janeiro não é mais feriado nacional, há uma tendência cada vez maior de os grupos transferirem a Festa de Chegada para o primeiro sábado ou domingo após o Dia de Reis.

(2) Embora a maioria das folias saiam à meia-noite da passagem para o Natal, há grupos que, por tradição, esperam até o Dia de Ano. 
cal. Aliás, em cada casa, as folias tendem a cantar de cinco a oito minutos em média, mas podem também se deter por muito mais tempo, sempre repetindo uma mesma "toada" (termo utilizado pelas folias para designar uma seqüência melódica). Sem dúvida, esta redundância não pode ser gratuita (Lomax e Halifax, 1968: 275): ela deve estar demonstrando a importância da estrutura musical da performance enquanto expressão de algo constitutivo da vida daqueles que participam direta ou indiretamente da tradição, independentemente do seu texto (Merriam, 1964; Blacking, 1973).

Tendo em vista esta lacuna na literatura sobre o assunto, neste trabalho tentaremos demonstrar o potencial que a perspectiva etnomusicológica pode trazer para a nossa compreensão da tradição das folias de Reis do Sudeste brasileiro, principalmente aquelas do sul de Minas Gerais. Em vez de olharmos as explicitações nos textos da cantoria, fartiremos dos seus aspectos sonoros, para tentarmos detectar alguns elementos da experiência concreta dos seus produtores, elementos estes que adquirem destaque peculiar em funçāo do modo como surgem na organização das vozes no interior do conjunto. Veremos, com este exemplo, que nāo é por acaso que as folias privilegiam determinados elementos na performance de sua música: elas estruturam seu universo sonoro de tal modo que sua cantoria explicita aspectos da sua visāo de mundo e do seu ethos. Trata-se, portanto, de mais uma maneira do grupo narrar para si mesmo a sua própria estória (Geertz, 1978: 443).

Optamos por enfatizar a cantoria, deixando de lado os aspectos referentes aos instrumentos musicais da tradição, devido ao fato de considerarmos a performance vocal mais próxima, biologicamente falando, do indivíduo - a voz vem do interior do corpo, ao passo que tocar um instrumento implica a manipulaçāo de um objeto externo -, de modo que, para uma primeira análise, um estudo da cantoria nos parece prioritário, podendo um estudo instrumental vir depois.

Embora haja duas formas básicas de organização vocal na regiâo da pesquisa, optamos por concentrar a análise sobre os grupos que empregam a "toada velha", um estilo que utiliza oito vozes distintas. Por se estruturar de forma mais complexa, explicita, com mais clareza, uma série de elementos também presentes na organização sonora de outros grupos, cuja cantoria emprega apenas cinco vozes diferentes.

Numa primeira observação da cantoria, nota-se que a estrutura básica de ambas as formas é essencialmente responsória, uma estrutura legada pela tradição judáica da Igreja Católica, sendo que, mesmo nos rituais oficiais da Igreja, esta forma de organização sonora persiste até os dias de hoje, graças, principalmente, ao Papa Gregório Magno (590-604) (Apel, 1944: 304-310). Relativamente à persistência da forma responsória utilizada nas folias, há de se mencionar a provável influência dos franciscanos também, que incorporaram, à sua forma de canto responsivo, os padrōes das cançōes dos menestréis e trovadores (Raynor, 1981: 59).

Esta forma musical evidencia claramente a presença de uma liderança, figura que, nas folias, E chamada de "embaixador", cabendo a ele um solo, onde há a improvisação de textos (ou versos) que os demais foliōes repetirão ritualmente na sua cantoria. Na verdade, as outras vozes văo entrando uma após a outra (ou èm blocos sucessivos), sendo que, somente no último acorde da cantoria de um verso, entre a última voz, conhecida como "tala" em algumas folias, "requinta" ou "finório" em outras. Este canta uma única 
nota aguda e bastante prolongada, que normalmente é executada por um préadolescente ou, mais raramente, por uma mulher. Logo à primeira vista, esta forma de distribuiçāo vocal nos remete à organização no campo social, haja vista que, além daquilo que pode ser observado facilmente por qualquer um, a literatura em todas as áreas das ciências humanas e sociais é farta no que diz respeito à subordinação das crianças e das mulheres - isto é, as pessoas vistas como improdutivas - aos homens.

Se esta primeira constatação nos permite dizer que a cantoria reflete aspectos da estrutura social, somente uma análise mais apurada nos permitirá perceber com mais precisāo uma série de nuanças referentes à forma de liderança e subordinação em que consiste o universo social explicitado na cantoria.

De fato, o embaixador tem um papel de grande destaque no grupo, o qual ele adquire por demonstrar, aos membros de sua companhia, a sua competência no domínio musical, pois há consenso entre a maioria dos foliōes de que esta funçāo exige certo "dom de Deus", reservado a poucos. ${ }^{3}$ Cabe observar que ele demonstra seu dom permanentemente nas performances de diversas maneiras. Primeiramente, como cabe ao embaixador improvisar os versos, sejam eles referentes às narrativas cantadas nos presépios, sejam eles os versos para abençoar os devotos, o líder só poderia improvisar tais textos tendo conhecimentos profundos da tradição, de modo que ele é o principal depositário de saber mitológico e ritual ligado às folias de Reis, o que lhe confere prestígio num contexto onde este saber é valorizado. Muitos foliōes esperam que os embaixadores tentem sempre improvisar textos diferentes, o que evidencia a extensão do seu saber bem como seu "talento" no uso das palavras, havendo, inclusive, uma série de situaçóes rituais justamente para botar à prova o conhecimento dos embaixadores. ${ }^{4}$

(3) Como já foi visto em trabalho anterior (Reily, 1985), a idéia do "dom" é bastante difundida na sociedade brasileira (e quiçá no mundo ocidental de modo geral), e tende a estar associada à positividade.

(4) Para receber uma folia, há famílias que preparam suas casas, expondo uma série de adivinhaçōes (como letreiros, velas e santos colocados em pontos estratégicos da casa), que o embaixador ou os palhaços devem desvendar para poder entrar ou sair de casa. Há também os Encontros de Folias, onde dois embaixadores e seus palhaços disputam seu saber mitológico, sendo que um embaixador desafia o outro em versos e este responde, também com cantoria. Se a resposta for satisfatória, cabe ao segundo embaixador desafiar o primeiro. Assim o ritual continua até que um embaixador seja declarado vencedor, e neste caso, o perdedor deve deixar seus instrumentos com a folia vencedora, ou decide-se pelo empate. 
Por outro lado, como em muitas tradiçōes musicais do repertório brasileiro - repente, cururu, brāo, ${ }^{5}$ coco, carangueijo 6 etc. - , seus versos têm que ser elaborados de tal modo a se encaixar numa estrutura melódica preexistente. Na verdade, esta forma de improvisação está muito próxima dos processos de composição "formulaica" empregados pelos bardos eslavos na performance dos seus épicos, cuja coleta feita por Milman Parry permitiu a análise de sua composição por Albert Lord (1960). ${ }^{7}$ Trata-se de uma técnica que permite ao compositor improvisar longas seqüências narrativas, mantendo seus versos em rimas e compostos por frases de tamanhos iguais, pois o cantor joga com um estoque de frases (as fórmulas), encaixando-as para formar os versos. Assim, aproximadamente $90 \%$ do texto da improvisaçāo prendem-se a este estoque de frases prontas. Mesmo que se possa compreender os processos em que a improvisação ocorre, a rapidez com que o cantor enuncia sua próxima frase, ou a capacidade de rimar uma seqüência de coplas, nāo podem ser desmerecidas.

Se o embaixador precisa improvisar de forma adequada, muitos foliōes dizem que a toada também deve ser composta pelo líder do grupo e, de preferência, mudada a cada ano, embora as composiçōes devam obedecer a algumas regras específicas, relativas à estética do gênero. Parte do status atribuído a um embaixador deriva do número de toadas que ele é capaz de produzir e manipular, sendo que grandes embaixadores podem até vir a ser homenageados e relembrados por seus companheiros, através do uso de uma de suas toadas.

Por o embaixador deter um vasto repertório de saber ligado à tradição, lhe é atribuído um papel fundamental enquanto intermediário entre os homens e o sagrado. Por isto, ele é procurado com certa antecedência, normalmente em sua casa, pelos membros da comunidade que têm uma promessa a cumprir no decorrer de uma jornada, sejam eles devotos com promessas mais simples, como carregar a Bandeira durante um percurso de sete casas ou oferecer um almoço ou jantar ao grupo de músicos, sejam aqueles com promessas mais dispendiosas e de maior responsabilidade, como assumir a Bandeira durante uma jornada inteira (isto é, tomar a posição de festeiro), ou "vestir" um filho de Bastiāo. O embaixador, então, orienta o devoto quanto às obrigaçōes envolvidas na função que exercerá ou, quando possível, ele mesmo assume responsabilidade pela "infra-estrutura" ritual necessária para o cumprimento da promessa. Por exemplo, para a Chegada da Bandeira, $\varepsilon$ necessário, em algumas folias, que se arme uma série de arcos de bambu, sob os quais a companhia passará antes de chegar no presépio ou altar final. Pode

(5) O "brāo" é uma forma de cantoria de adivinhação utilizada nos mutirōes para roçar o pasto no Vale do Paraíba. Um estudo sociolingüístico deste gênero musical está sendo feito por Débora Jane Schisles, como tese de mestrado na PUC de São Paulo.

(6) O "carangueijo" é uma forma dançada nos bairros afastados do Vale do $\mathrm{Pa}$ raíba, quando de uma pousada da Folia do Divino ou em outras ocasiōes de sociabilidade.

(7) Albert Lord era assistente de pesquisa de Nilman Parry na Iugoslávia e participou da coleta dos épicos, com os quais Parry pretendia expor sua teoria de composição formulaica, o que nunca ocorreu, dada sua morte prematura. 
ser que o festeiro providencie o material e sua armação, mas pode ser que o próprio embaixador se encarregue disto, com a ajuda dos seus foliōes.

Por outro lado, o embaixador também tende a exercer um papel de mediação entre os foliōes e os devotos com o mundo externo, principalmente no que se refere à aquisição de benefícios para o grupo. ${ }^{8}$ Daí, cabe a ele estabelecer os contatos em favor da comunidade com outros grupos performáticos para a troca de homenagens, mas também com pesquisadores, instituições públicas e firmas, na tentativa de adquirir fardamentos, instrumentos, convites para apresentaçōes "folclóricas", refeiçōes e muitos outros benefícios.

Até aqui, vimos como há uma relação estreita entre a posiçāo de embaixador na cantoria e seu papel enquanto líder social do grupo e da comunidade em que vive. Após o seu solo, no estilo da toada velha, entra o "resposta", para repetir - ou responder - a segunda linha da embaixada junto com a primeira voz, embora sua voz se localize uma terça acima da voz principal. As vezes esta nova voz é chamada de "segunda", termo também freqüente entre os caiçaras estudados por Kilza Setti (1985), ou até mesmo "ajudante", mesmo que, na toada velha, este termo indique a terceira voz do conjunto. Normalmente quando se trata de um segunda, desde o início da cantoria do embaixador, esta voz procura fazer um dueto com a voz principal na terça superior, em alguns raros casos na terça inferior, sendo que o cantor da voz procura prever o que o líder irá cantar. Por isto, esta voz tende a estar sempre um pouquinho atrasada na enunciação do texto, mas o ouvinte percebe uma certa constância das terças paralelas.

A primeira alternativa tem semelhanças com aquilo que Lomax e Grauer chamam de "alternaçāo sobreposta com dominação de um líder", enquanto a segunda está mais próxima de um "uníssono social com dominação de um líder" (1968: 39-40). Ao comentar a primeira alternativa, Lomax nos dá o exemplo da cantoria nas igrejas protestantes dos negros do sul dos Estados Unidos, relacionando a estrutura da música ao papel do pastor.

Independentemente do poder que o pastor possa ter, (...) sua permanência depende de contato direto com seus auxiliares e com a sua congregação, assim como o sucesso dos seus sermões seria julgado pelo retorno rítmico que evocariam entre os fiéis (1963: 161, traduçāo da autora).

Com este exemplo, podemos ver como há indícios de que tal alternativa de organização sonora sugere a integração do líder na sua comunidade, sendo que uma situação de ainda maior integração entre a liderança e o grupo estaria sugerida num uníssono com dominação de uma voz sobre as outras.

Com efeito, um caso narrado pelo líder social de uma folia pesquisada exemplifica bem a forma de liderança que se espera do embaixador: uma

(8) A forma de liderança voltada para a mediaçāo entre os foliōes e o mundo externo lembra muito os líderes dos "garotos da esquina", entre os migrantes italianos em Boston durante a Depressão, atuação descrita por William Foote Whyte (1981). 
certa firmeza sem que se desrespeite os companheiros. O próprio fato de os foliōes se referirem uns aos outros como companheiros (colegas, amigos) reforça a noção de que a liderança efetivamente faria parte do grupo. Pois bem, o responsável pela Bandeira desse grupo convidou um foliāo para assumir sua companhia, no entanto a experiência foi negativa, pois o embaixador, apesar de ser particularmente reconhecido pelo seu saber mitológico e ritual, chegava a chamar a atenção dos seus subordinados publicamente, quando não estivesse satisfeito com suas performances ou com seu comportamento. Os foliōes protestaram junto ao dono da Bandeira, dizendo que s 6 sairiam para ele de novo caso o embaixador fosse substituído. No próximo ano já havia outro embaixador na companhia, este mais em compasso com as concepçōes da liderança dos membros da folia.

Tudo indica, contudo, que cabe mesmo à liderança zelar pela performance bem como pela disciplina interna da companhia, principalmente no que se refere à bebida alcoólica. ${ }^{9}$ No entanto, em casos de insatisfaçāo com um determinado foliāo, o líder precisa saber comunicár seu desagrado, seja através de um olhar sutil, seja com um comentário genérico para o grupo como um todo. Se isto não funcionar, o embaixador pode tentar conversar com o foliāo em particular bem como botar outros foliōes, especialmente aquele que canta a voz de resposta, para ajudar a pressioná-lo.

$\mathrm{Na}$ medida em que os foliōes tendem a participar de uma companhia por opção pessoal, que, além de ser um meio de expressar sua devoção aos Três Reis, lhes proporciona lazer, um espaço para a sociabilidade bem como alguns benefícios materiais ou mesmo de destaque perante a comunidade, eles podem entrar e sair das companhias conforme lhes convier. Assim, o cultivo de um espírito de companheirismo no interior das folias é fundamental para a própria sobrevivência do conjunto. Pode-se concluir, portanto, que a cantoria das companhias se estruturaria de tal modo a englobar a diferenciação hierárquica da composição do grupo como uma noção de "comunalidade", sendo que ambos estes conceitos, aparentemente contraditórios, estāo embuticos simultaneamente na organização sonora das folias de Reis.

Se há esta dupla face na cantoria, ela se torna ainda mais explícita ao notarmos que a segunda voz encontra-se numa terça paralela acima da voz principal. Cantoria em paralelismo apresenta alguns aspectos também necessários ao uníssono, já que o texto, o ritmo, os intervalos e os ataques deverāo ser enunciados por todos os cantores com certa coordenação conjunta. Afinal, paralelismo pode ser visto como a duplicação da melodia numa outra tonalidade (Hood, 1971: 304). A performance desta prática exige muita disciplina e conformidade, já que, durante a duraçāo da cantoria, todos os participantes terāo que concordar em se ajustar ao padrão dado pela estrutura melódica e seu texto (Lomax, 1963: 155).

Em termos tonais, contudo, os cantores nāo estāo cantando a mesma coisa, de modo que cada voz pode ser distinguida com relativa facilidade, dependendo, evidentemente, do número de vozes no conjunto. Este nāo tende a ser o caso no canto em uníssono propriamente dito.

(9) Esta é uma preocupaçāo constante entre os foliōes, já que a bebedeira é um problema que, de acordo com muitos entrevistados, faz com que muitas famílias não queiram receber uma companhia em suas casas. 
Para compreendermos melhor este aspecto da cantoria, poderia ser útil olharmos a questão da perspectiva da evolução, na música ocidental, da polifonia, música com distinçāo de vozes em que se pretende um conjunto harmônico. Há registros dos seus primórdios já na cantoria da Schola Cantorum do Papa Silvestre (314-335). Numa forma de canto responsivo, cabia às scholas (termo que veio a designar os primeiros corais da Igreja) responder ao texto com o canto de uma única palavra, como amém ou aleluia, ou mais tarde com uma frase. Conforme os textos das respostas se complexificavam. os cantores da Igreja tornavam-se cada vez mais especialistas da música, executando alternaçōes entre um solista e um coral ou entre dois corais, como o dos homens e o dos meninos, que cantavam uma oitava acima do grupo principal. A polifonia, usando o termo num sentido mais próximo a seu significado atual para o mundo ocidental, provavelmente originou-se na França, sendo que lá empregava-se o órgano de quartas e quintas abaixo da voz principal já no século IX. A partir do século XII, as notas paralelas passaram a correr acima do cantus firmus, sendo que se conseguia um efeito de quatro vozes com os meninos cantando na oitava acima de cada uma das vozes dos homens (Apel, 1944; Raynor, 1981).

Quanto à terça paralela, o gymel, na tradição ocidental, provavelmente este tem sua origem na Inglaterra por volta do século XIII, mas há indicaçōes que também era conhecido na França por volta do mesmo período, mesmo que seu uso fosse mais restrito (Apel, 1944: 315). De todo modo, este procedimento polifônico pode ser encontrado em várias tradiçōes do mundo, inclusive em muitas regiöes sem ligaçōes ocidentais (Gergley, 1967). No entanto, as coletâneas do cancioneiro nacional atestam seu largo emprego na música brasileira de origem européia. Basta dar uma verificada nas transcriçōes de Mário de Andrade (1928; 1958), Oneyda Alvarenga (1982), Kilza Setti (1985) e muitos outros.

Referente ao cancioneiro brasileiro, esta difusão certamente não se deve meramente a um genérico gosto estético, como querem alguns autores. Para compreendermos a questão no contexto nacional, convém refletirmos sobre as razōes pela tendência, na Idade Média, da duplicação melódica acima do cantus firmus, mesmo durante o período em que o órgano era colocado abaixo dele. Aliás, a posterior transferência da voz principal para o registro mais agudo no canto coral da Igreja só ocorreu de modo mais sistemático na $\mathrm{Re}$ nascença, com o desenvolvimento do hino protestante (Einstein, 1956: 61).

De fato, as vozes agudas tendem a sobressair-se num conjunto musical caso todos cantem na mesma intensidade. Isto ocorre por questōes que talvez a psicologia Gestalt possa explicar. As vozes agudas no conjunto das folias de Reis são justamente aquelas que se encontram no registro confortável das crianças e das mulheres, uma questão determinada por fatores biológicos de caráter universal. Daí, é de se supor que a duplicação melódica do paralelismo medieval acima da voz principal - uma inversão da alternativa mais "natural", por assim dizer - ocorreu por questōes de ordem social, sendo que isto também deve ser verdade com relação à distribuição de vozes no interior das folias de Reis. A estrutura fortemente hierarquizada da Idade Média, onde havia clara dominação masculina sobre as mulheres e crianças, fora transposta para o domínio estético da música. Há, inclusive, evidências que nos levam a crer que foi só depois que os trovadores e os trouvères desenvolverem o lirismo e, com este, a idéia da musa, durante a Alta Idade 
Média, que foi possível a conquista da posiçāo de proeminência no conjunto coral pelas sopranos, no decorrer do século XVI, principalmente na Itália (Einstein, 1956).

Sāo raríssimas as exceçōes em que a cantoria das folias de Reis apresentem esta mesma transferência da voz principal para o registro superior: quando isto ocorre, tal construção nāo tende a persistir por toda a cantoria de uma toada. 10 De modo geral, quanto mais grave a voz do foliāo, tanto mais elevada a sua posição na hierarquia do grupo, uma opção estética que, sem dúvida nenhuma surge de uma associação entre o registro agudo e subordinaçāo, dada a associaçāo - quiçá universal - entre o tom agudo e mulheres e crianças.

Há, contudo, que se ressaltar que, na cantoria das folias, principalmente naquelas que empregam o estilo da toada velha, desenvolveu-se um jogo permanente em que a proeminência das vozes passa sutilmente $-e$ as vezes não tāo sutilmente - de um registro para o outro. Isto ocorre durante momentos específicos da performance de um verso, embora o cantus firmus sempre permaneça no registro mais grave, o qual nāo precisa necessariamente ser cantado pelo embaixador.

Pois bem, se o resposta executa uma parte de sua cantoria na terça acima da voz do embaixador, é bem provável que esta preferência estética indique sua posição de subordinação à liderança, posição que seu cantador tende mesmo a ocupar em quase todas as folias. No entanto, na estrutura da cantoria da toada velha, o embaixador pára de cantar após seu pequeno dueto com - resposta e este assume seu registro, enquanto o "ajudante" (terceira voz na hierarquia do grupo) e o "contrato" assumem registros mais agudos que, embora nāo sejam exatamente vozes paralelas, também não apresentam grandes contrastes em movimento, de modo que podem ser vistos como a terça e a quinta superiores, respectivamente. Esta configuração vocal dura apenas oito compassos.

Dada esta distribuição de vozes na cantoria, não surpreende constatar que muitas vezes durante uma jornada o resposta pode vir a substituir o embaixador na sua ausência ou num momento de cansaço, de modo que ele também precisa saber embaixar, usando o seu próprio estilo. Cabe lembrar que, no campo social, há casos em que ele pode partilhar da liderança com o embaixador, ou mesmo substituí-lo por completo nas tarefas do domínio social. Nota-se, inclusive, uma tendência quanto à participação do resposta, ou segunda, na liderança do grupo, aumentada na proporçāo do espaço que lhe é dado para embaixar a folia.

Repensando a cantoria do resposta no seu conjunto, observa-se que, em circunstâncias normais, ele cantaria seis compassos em dueto com o embai-

(10) Há, na cantoria das congadas desta regiāo, a tendência da voz principal estar no registro mais grave, embora, na música sertaneja, outro gênero musical comum ao universo da população em questāo, a voz principal tenda a ser a mais aguda. É possível que isto ocorra por este repertório estar mais próximo de uma forma lírica que os gêneros associados mais diretamente com a expressão religiosa. 
xador e oito na segunda configuraçāo, onde assume o registro do líder. Em outras palavras, poderíamos dizer que, primeiramente, ele canta complementando a performance do embaixador, enquanto num segundo momento ele o substitui, embora utilize o texto determinado pelo cantor da voz principal. Que metáfora seria útil para a compreençāo desta estrutura de relaçōes interpessoais?

Na medida em que a tradiçāo como um todo gira em torno da família afinal ocorre na época de Natal, a grande festa da família, através de cantoria em casas de famílias - não é excessivamente fora de propósito invocarmos esta metáfora para compreendermos a organizaçāo do grupo, vendo-a como paradigma de relações sociais para o contexto mais amplo. Estariamos, entāo, diante de uma noção a respeito das relaçōes familiares e o papel da liderança na família, isto $e$, da relação do casal, entre si e com a família intei$\mathrm{ra}$, onde o embaixador exemplificaria o pai e o resposta a mãe? Ora, na cantoria individualizada, explicita-se uma hierarquia familiar, e no que diz respeito ao casal, canta-se primeiramente para o dono da casa, para então cantar para sua senhora, mas muitas vezes, o primeiro verso é dedicado ao casal enquanto unidade, sem distinçāo dos seus componentes. Quando não há um "homem da casa", canta-se para a dona da casa. Se o texto, com esta terminologia específica, explicita algo sobre a posição de liderança familiar, a organização vocal da cantoria pode ser mais explícita com relaçāo à noção normativa do relacionamento apropriado ao casal: o pai/marido enquanto figura que faz a intermediaçāo entre a familia e o mundo externo, de modo que ocupa a posição central deste núcleo, e a mãe, seu complemento, sendo que a dupla forma uma unidade harmônica: na ausência do pai, a mãe poder vir a substituí-lo perante os filhos e a comunidade, fazendo valer as palavras predeterminadas pelo marido ausente. Enquanto metáfora, este conceito referente às relaçōes sociais poderia ser estendido de modo a englobar um campo mais amplo, até porque ele parece estar sendo reproduzido na organização deste conjunto musical.

$*$ * * *

O contrato, por sua vez, está em particular evidência durante este curto pedaço da execução de um verso, na medida em que, além de estar na voz superior, que por si só já the confere destaque, um bom performer desta voz precisa saber enfeitá-la, divergindo propositadamente de uma duplicação exata da melodia. Além de um pequeno contracanto sobre as notas prolongadas ao final do dueto do embaixador com o resposta, o contrato tende a adicionar alguns ornamentos melódicos a sua cantoria bem como algumas incrementaçōes rítmicas, através de atrasos e ataques bem acentuados. Este também tende a cantar com mais volume que o resposta e o ajudante e, mais que os outros foliōes, os contratos tendem a entrar no balanço da música, movimentando-se no ritmo de sua cantoria. Cabe ressaltar que todos estes elementos fazem com que a voz adquira destaque no conjunto, podendo o ouvinte e observador distingui-la das outras vozes com mais facilidade. 
Se, na estrutura da toada velha, o contrato está em particular evidência, isto também é verdade em outros estilos freqüentes na região do sul de Minas, onde o contrato faz sua entrada na frase antes do acorde final, seja na oitava acima da primeira voz, seja na oitava do segunda. De todo modo, o próprio registro de sua cantoria faz com que a voz sobressaia no conjunto vocal, mas cabe observar que sua performance tende a exigir muito volume, dando à voz ainda mais destaque, mesmo que, nestas folias, seu performer nāo incremente a linha melódica, como ocorre no estilo da toada velha.

Se dermos continuidade à nossa metáfora, poderfamos dizer que esta voz representa o filho mais velho que, tornando-se homem, mostra-se mais independente do conjunto, isto é, logo poderá estabelecer sua própria família. Aliás, nāo são raras as folias em que o cantador do contrato seja o "galāzinho", por assim dizer, da companhia.

E interessante notar também que, terminados os oito compassos da configuraçāo resposta/ajudante/contrato, a voz mais aguda cai do registro da tônica para o da dominante inferior e, sob esta voz, constrói-se uma nova configuração vocal que apresenta certa independência musical das duas vozes abaixo dela, a do resposta com o ajudante, configuração esta que poderia ser vista como uma nova familia, oriunda da configuração anterior.

Ao passo que os cantores de "trás", o "cacetero", o "tipe" e o "contratipe" 11 executam os últimos dez compassos da toada sobre a voz do contrato, somente na última nota da cantoria entre o tala, fechando o acorde com a tônica superior. Este acorde tem duração de quase três compassos em algumas folias, podendo ser muito mais comprido na cantoria de outros estilos. Talvez este acorde seja um dos elementos mais característicos da tradição das folias de Reis. Este elemento musical dá um arremate apotético as toadas, e provavelmente constitui uma forma mais complexa do efeito sonoro pretendido pelas scholas da Idade Média.

De fato, este acorde final é elemento privilegiado de avaliaçāo por parte dos foliôes e da comunidade que participa da tradição, sendo que todos observam com particular atenção a competência do tala bem como aspectos do conjunto na sua execução do acorde, como a afinação do grupo, a duração do acorde (quanto mais prolongado melhor) e seu volume (quanto mais volume melhor).

Como vimos anteriormente, a voz do tala tende a ser executada por uma criança pré-adolescente ou por uma mulher. Se a organização das vozes espelha elementos relativos à hierarquia familiar, estas últimas vozes poderiam

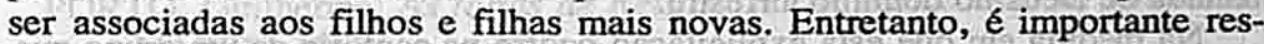
saltar que, com relaçāo a esta voz, justamente a que se poderia pensar ser a mais desprestigiada, diz-se dela que é muito difícil encontrar alguém que consiga executá-la satisfatoriamente, já que $\hat{\epsilon}$ extremamente aguda e, como o contrato, deve sobressair no conjunto, de modo que exige muito volume e

(11) Provavelmente todos estes termos sāo corruptelas de termos da música medieval. Por exemplo, "cacetero" pode vir de caccia, uma forma canônica que teve origem na França, por volta de 1300, assim denominada por a segunda voz "caçar" a anterior. Do mesmo modo, "tipe" provavelmente venha de triple, termo usado para designar uma voz aguda. O termo "tala" pode ser corruptela de taille, sendo que havia tanto a haute taille quanto a basse taille, uma aguda e a outra grave, respectivamente. 
controle da respiração. Na ausência de um bom tala, muito do efeito apoteótico do acorde final fica perdido.

Enfim, se a cantoria š estrutura de modo a demarcar as posiçōes relativas dos membros do grupo, há também um jogo permanente, nas performancés, em que, em momentos distintos, dá-se destaque, mesmo que restrito, a vozes hierarquicamente inferiores. Ou seja, é possível dizer que, embora, através da organização vocal, afirme-se que cada um ocupa um lugar diferente numa estrutura de posiçōes escalonadas, a importância individual de cada um também é explicitada, importância esta adquirida precisamente em função da peculiaridade da voz do cantor.

Se voltarmos nossa atenção para o acorde apoteótico, observaremos uma clara explicitaçāo da valorização de algo que poderíamos chamar de uma "igualdade diferenciada", onde o conjunto como um todo está em harmonia. Haja vista que, em algumas folias, $\mathrm{o}$ acorde do arremate chega a se estender por vários compassos, havendo casos em que representa mais de um terço de toda a cantoria de um verso, é de se supor que esta opçāo estética explicitaria uma noção estruturante da visāo de mundo dos membros das companhias bem como das comunidades ligadas à tradição.

No início deste trabalho afirmamos que o ritual da jornada das folias de Reis prestigia três níveis de famílias: a Família Sagrada, a família nuclear e a "familia" do conjunto dos cristāos aqui na terra. Quase todas as formas de organização vocal das companhias observadas no decorrer da pesquisa distinguem pelo menos três complexos vocais que poderiam ser vistos como representaçōes simbólicas desses três níveis familiares. Há, primeiramente, o embaixador que, intermediando entre os seres humanos e o sagrado, proclama as profecias, trazendo a palavra de Deus - ou o "verbo" - para a terra, de modo que se forma a primeira configuração vocal: embaixador, resposta, ajudante; em segundo lugar, surge uma configuração sobre a voz do contrato, derivada da primeira, formando o que poderia ser visto como uma espécie de família nuclear; e, por fim, no acorde prolongado, onde todas (ou quase todas) as vozes cantam em conjunto, estabelece-se a grande comunidade irmanada de Deus no domínio terrestre.

Na medida em que esta explicitaçāo ocorre na cantoria de um grupo que nāo precisa necessariamente estar relacionada por laços de parentesco, mas, mesmo assim, aparentemente estrutura sua cantoria bem como seu convívio social "extra-ritual" a partir da metáfora da família, é de se supor que esta mesma metáfora seja transposta também para outros domínios do universo social. É possível, inclusive, que sua própria noção de coesão social parta desta metáfora, de modo que as relações de trabalho e o universo político sejam avaliados positiva ou negativamente, conforme sua capacidade de refletir esta estrutura normativa. Atrevo-me até a sugerir que concepçōes análogas permeiem todo o universo do catolicismo popular brasileiro e, quiçá, latino de modo geral, sendo mesmo elemento estruturante da visão de mundo e do ethos da tradiçāo católica. 
ALVARENGA, Oneyda. Música popular brasileira. São Paulo, Duas Cidades, 1982.

ANDRADE, Mário de. Ensaio sobre a música brasileira. São Paulo, Chiarato, 1928.

- Danças dramáticas do Brasil. São Paulo, Martins, 1958.

APEL, Willi. Harvard dictionany of music. Cambridge, Mass., Harvard University Press, 1944.

ARAÚJO, Alceu Maynard de. Folias de Reis em Cunha. Revista do Museu Paulista, (3):413-65, 1950.

-. Folclore nacional. São Paulo, Melhoramentos, 1964.

BLACKING, John. How musical is man? Seattle, University of Washington Press, 1973.

BRANDĀO, Carlos Rodrigues. A folia de Reis de Mossâmedes. Rio de Janeiro, FUNARTE, 1977.

Sacerdotes da viola. Petrópolis, Vozes, 1981.

CASTRO, Zaíde Maciel de \& COUTO, Aracy do Prado. Folias de Reis. Rio de Janeiro, FUNARTE, 1977.

EINSTEIN, Alfred. A short history of music. New York, Vintage Books, 1956.

GEERTZ, Clifford. A interpretaçāo das culturas. 1978.

- GERGELY, Jean. Histoire ilustrée de la musique. Lausanne, La Guide de Disque/Rencontre, 1967.

HOOD, Mantle. The ethnomusicologist. New York, McGraw-Hill, 1971.

LOMAX, Alan. Song as a measure of culture. In: __, org. Folk song style and culture. Washington, D.C., American Association for the Advancement of Science, 1968. p. 117-60.

- \& GRAUER, Victor. The cantometric coding book. In: LOMAX, Alan, org. Folk song style and culture. Washington, D.C., American Association for the Advancement of Science, 1968. p. 34-74.

\& HALIFAX, John. Folk song texts as culture indicators. In: LOMAX, Alan, org. Folk song style and culture. Washington, D.C., American Association for the Advancement of Science, 1968. p. 274-90.

LORD, Albert. The singer of tales. Boston, Harvard University Press, 1960. MERRIAM, Alan P. The anthropology of music. Evanston, III., Northwestern University Press, 1964.

PORTO, Guilherme. As folias de Reis do sul de Minas. Rio de Janeiro, FUNARTE, 1977.

RAYNOR, Henry. História social da música. Rio de Janeiro, Zahar, 1981.

REILY, Suzel Ana. A Senhora do Divino. Cadernos de Pesquisa, (52): 16-25, 1985.

SETTI, Kilza. Ubatuba nos cantos das praias: estudo do caiçara paulista e de sua produção musical. São Paulo, Ática, 1985.

TAVARES DE LIMA, Rossini. O folclore do litoral norte de São Paulo. Rio de Janeiro, FUNARTE, 1981.

WHYTE, William Foote. Street corner society. Chicago, University of Chicago Press, 1981.

ZALUAR, Alba. Os homens de Deus: um estudo dos santos e das festas no catolicismo popular. Rio de Janeiro, Zahar, 1983. 


\begin{abstract}
This is an ethnomusicological analysis of the Folias de Reis in the Southeastern region of Brazil. The Folias are made up of a group of musicians that roam from house to house during the Christmas season, as a form of devotion to the three Wise Men. In an attempt to understand the logic behind the distribution of the voices within the song style, I concentrated the analysis on the style the musicians call "old tune", for it is the most complex form found in the region of the research project. Since I noted that the vocal organization reflects normative notions regarding family structure among the communities that participate in the tradition, we can view the music as a social construction, in which the group says something fundamental about its own worldview.
\end{abstract}

Key words: Folia de Reis - Ethnomusicology - Family structure - Social cohesion 